\title{
Study on the Slope Bolt Support Design Based on GIS
}

\author{
Junlan Zhao* and Huarui Wu
}

College of Civil Engineering, North China University of Technology, Beijing 100144, China

\begin{abstract}
As the main means of monitoring and early warning of geological disaster, the slope stability analysis is an important part of the geological disaster prevention project. GIS plays an important role in the evaluation of slope stability due to its powerful functions for data processing and spatial analysis. This article discusses the key technology of GIS applied in the slope bolt support design. According to the bolting design specifications and GIS platform combined with the limit equilibrium theory, the slope bolting design module was developed. The automatic management of the design process and visual output of the design results can be realized in this module. The project of Sichuan Saide Slop Engineering was evaluated quantitatively and qualitatively using this module system. The result showed that the module system was feasible and the effect was accurate.
\end{abstract}

Keywords: GIS, slope stability, limit equilibrium, bolt support.

\section{INTRODUCTION}

Western China is the area where natural disasters happened frequently and seriously. The disasters brought the huge economic losses to the local and gave the great threat to people's life and property. How to support the latent landslide slopes timely and reasonably is an imminent work.

At present, the measures of strengthening slope mainly include bolting, retaining wall, anti-slide pile and so on. The combination of GIS and slope supporting design has become one of the major development directions of the slope stability evaluation along with the development of computer technology. GIS techonology plays an important role in slope stability evaluation and landslide treatment design due to its powerful functions for data processing and spatial analysis [2]. The GIS mapping function can directly output the specific plans and design drawing of bolt support. The optimum proposal of slope bolting was designed using GIS powerful capability of secondary development, which realized the digitization and informatization of the slope deign management.

Take Sichuan Saide open slope for an example, the module system was designed. The result showed that the module system was feasible and the effect was accurate.

\section{PRINCIPLE OF BOLT SUPPORT DESIGN}

\subsection{Section Computation of the Bolt [3]}

Section computation of the bolt will be determined by means of following formula:

$$
A_{s} \geq \frac{K_{t} N_{t}}{f_{y k}}
$$

$\mathrm{Kt}$ - tensile-strength safety factor of the bolt

$\mathrm{Nt}$ - design value of the axial tension of the bolt $(K N)$

$f_{y k}$-standard value of axial tensile strength $(\mathrm{KPa})$

\subsection{Calculation of the Anchorage Length of the Bolt [3]}

The anchorage length of the bolt can be estimated by means of following formula, of which the bigger one will be chosen:

$$
L_{a}>\frac{K N_{t}}{\pi D f_{m g} \phi} \text { or } L_{a}>\frac{K N_{t}}{n \pi d \xi f_{m s} \phi}
$$

La- anchorage length of the bolt (m), 3-8m adopted for rock bolt, $6-12 \mathrm{~m}$ for soil bolt;

$\mathrm{K}$ - safety factor of the uplift bearing of the bolt

Nt- design value of the axial tension of the bolt $(\mathrm{KN})$

D- drilling diameter of the anchoring (mm);

d- diameter of the rebar or Steel Strand ( $\mathrm{mm})$;

$f_{m g}$ - standard values of bond strength between stratum and the anchoring (KPa);

$f_{m s}$ - standard values of bond strength between stratum and the rebar $(\mathrm{KPa})$;

$\xi$ - decreasing coefficient of the adhesive strength by using two pieces or more rebar, using 0.6-0.85;

$\phi$ - the influence coefficient of anchorage length of bond to adhesive strength (m);

\subsection{Calculation of Safety Factor after Reinforcement of the Bolt [4]}

Stability analysis of anchored slope is carried out by simplified bishop method. Take anchoring force as tensile reflect that upon the bottom of the bar, calculate the buckling safety factor Fs according to the simplified bishop method of 
the natural slope. The calculation diagram is shown in Fig. (1).

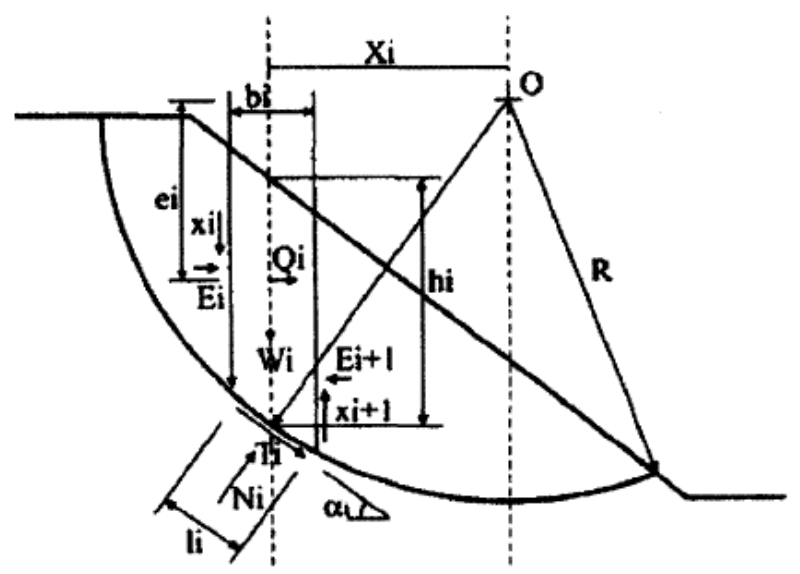

Fig. (1). The stress analysis diagram of the bolt support.

The stability formula of the anchored slope can be derived according to the simplified bishop method:

$F_{S}=\sum_{i=1}^{n} \frac{1}{m_{a i}} \cdot \frac{W_{i} \tan \varphi+c l_{i} \cos \alpha_{i}}{\sum_{i=1}^{n} W_{i} \sin \alpha_{i}}+\frac{\sum_{j=1}^{m} \frac{T_{j}}{S_{h}}\left(\sin \beta_{j} \tan \varphi_{j}+\cos \beta_{j}\right)}{\sum_{i=1}^{n} W_{i} \sin \alpha_{i}}$

Among them, $m_{\alpha i}=\cos \alpha_{i}+\frac{F_{S}}{\tan \varphi \sin \alpha_{i}}$

$n$ - sub-section number;

$m$ - bolt number;

$c$ - soil cohesion $(K p a)$;

$\varphi$ - internal friction angle $\left(^{\circ}\right)$;

Wi - soil density $(K N / m 3)$;

$\alpha \mathrm{i}$-soil slip angle $\left(^{\circ}\right)$;

$\beta$ i-horizontal inclination of anchor bars $\left(^{\circ}\right)$;

Ti-anchored force $(K N)$;

\section{FUNCTIONAL MODULE DESIGN}

\subsection{Technical Route}

During the design process, the arrangement of anchor rod (rope) should be considered (horizontal spacing, interval space). Then, the bolt should be checked in tension, drawing and global stability to find the length of anchor rod (rope), inclination, sectional dimension for designing. The problem of optimization of the anchor rod (rope) can be transformed into the problem of searching the minimum of the constraints. Namely, the sectional area of anchor rod is the smallest and the material to make it will be the least when the safety requirement can fully be met.

Combined with the graphic processing and the excellent secondary development capabilities of GIS, the module of support design of the anchor rod (rope) was developed by using the experimental method [5]. Then experimental method is to search the feasible point which can meet the constraint equation among the range of the sectional dimensions. The minimum can be found by comparing these objective function values (sectional dimensions). The objective function and constraint equation are as follows:

(1) Objective function: to take anchor rod (rope) properties as an independent variable, including the length of the anchor rod (rope), sectional dimension, anchorage length.

(2) Constraint equation: anchor rod (rope) should meet the requirements of security and section rationality, including tensile strength, uplift bearing capacity, global stability.

\subsection{Process of the Bolt Support Design}

The bolt support engineering is applied to the design of the instable slopes and the management of the deformation slopes. Often, more than one supporting programs should be designed. Based on the information and scientific prediction, combined with the existing technical level and engineering geology, the feasible solution set can be set up. The optimum plan was chosen on the basis of the feasible solution set. The choice of the slope supporting scheme is an optimal decision problem. The support scheme can be constrained by technology, economics, geology, engineering purpose and so on. Therefore, we should put forward several strengthening measures according to the geological conditions, construction conditions and engineering purposes.

The flow chart of bolt support design is shown in Fig. (2). The interface of the rod supporting design is shown in Fig. (3).

During the design process, the checking to tension, drawing and global stability of the bolt will be carried out by the program according to the data entered by the user. If the constraints cannot be met, the program will automatically adjust the anchorage length of anchor rod (rope) and the embedded angle until conditions are met. After calculation, the program will output the design results and the related arrangement of the anchor rod (rope).

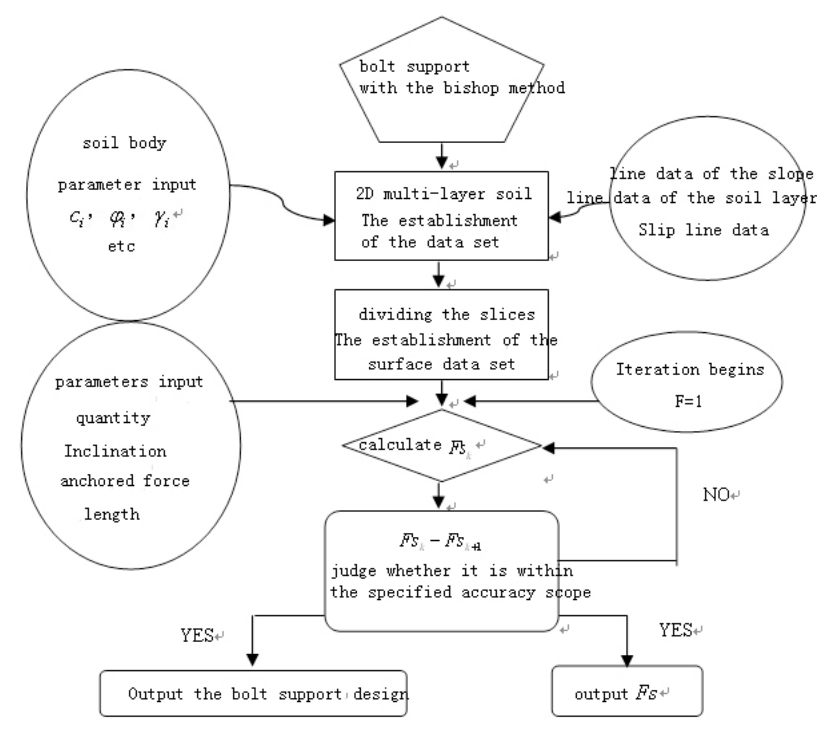

Fig. (2). Flow chart of bolt support design. 


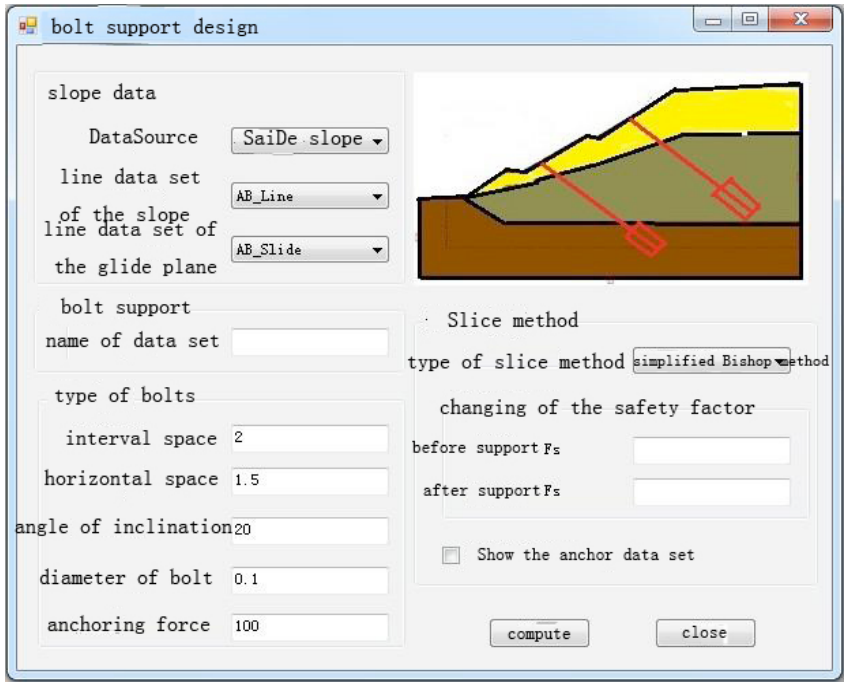

Fig. (3). Design interface of the rod supporting.

Among them, procedure of the overall stability checking is as follows:

'Before supporting

For $\mathrm{i}=1$ To Slice.Count

mFi_B = Math.Cos(Alfa(i - 1) * Math.PI / 180) + Math.Tan(Fi(i - 1) * Math.PI / 180) * Math.Sin(Alfa(i - 1) * Math.PI / 180) / Fs_B_acc

'There were only F_Bup1, F_Bup2 before supporting

F_Bup1 = F_Bup1 + W(i - 1) * Area(i - 1) * Math.Tan(Fi(i 1) * Math.PI / 180) / mFi_B

F_Bup2 = F_Bup2 + CL(i - 1) * Math.Cos(Alfa(i - 1) * Math.PI / 180) / mFi_B

' Added F_Bup3, F_Bup4 after supporting

F_Bup3 = F_Bup3 + (Tk(i - 1) / Sk(i - 1) ) * Math.Sin $($ Beta $(\mathrm{i}$ - 1) * Math.PI / 180) * Math.Tan(Fi(i - 1) * Math.PI / 180)

F_Bup4 = F_Bup4 + $(\mathrm{Tk}(\mathrm{i}-1) / \mathrm{Sk}(\mathrm{i}-1)) *$ Math.Cos $($ Beta $(\mathrm{i}$ - 1) * Math.PI / 180)

F_Bdown $=$ F_Bdown $+\mathrm{W}(\mathrm{i}-1) * \operatorname{Area}(\mathrm{i}-1) *$ Math.Sin(Alfa(i - 1) * Math.PI / 180)

'Bbefore supporting

Fs_B $=($ F_Bup1 + F_Bup2) $/$ F_Bdown

' After supporting

Fs_B $=($ F_Bup1 + F_Bup2 + F_Bup3 + F_Bup4 $) /$ F_Bdown Next

\subsection{Output of the Bolt Support Results}

Through 2D multi-layer support module, the factor of safety FS can be calculated by the simplified bishop method. The system can carry out the bolt support design automatically by comparing the safety factor before and after the supporting. The design results can be shown on the interface (Fig. (4)).
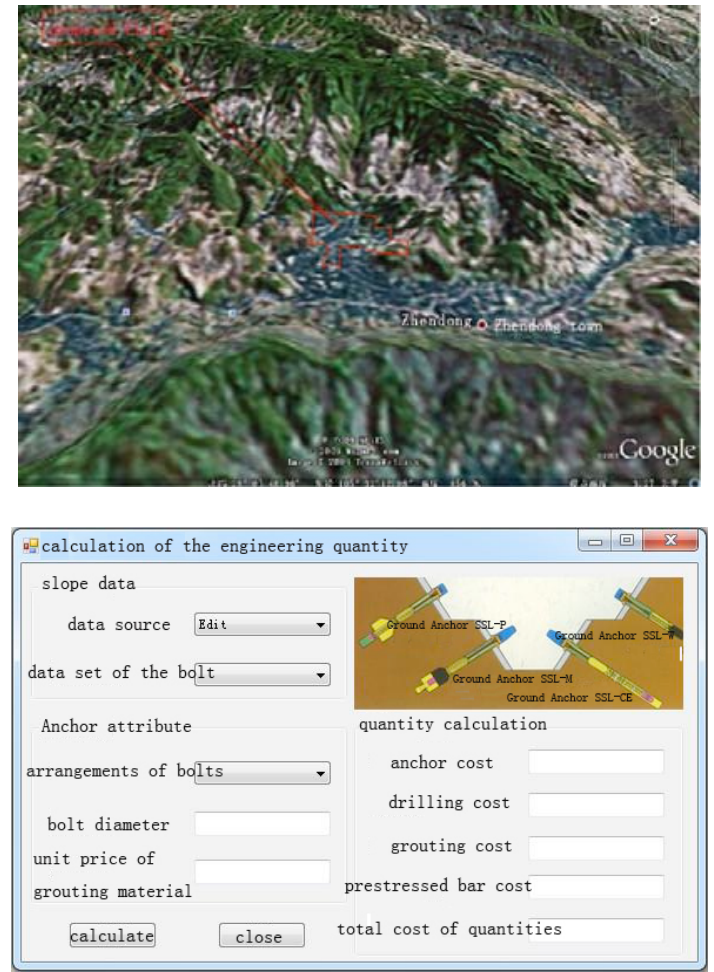

Fig. (4). Engineering calculation module of the bolt support.

\section{APPLICATION TO ENGINEERING}

\subsection{Project Profile}

Saide slope is located in the valley of the lower hilly areas of northern Sichuan, which is surrounded by mountains in north, south and east. The landform undulates terribly. According to the to-be-constructed planning drawings, the slope length is $1578 \mathrm{~m}$, the geological conditions is complex.

Slope stability extremely influence on the engineering construction. Moreover, the amount of fill is great and the engineering construction will greatly destroy the slope geological conditions. According to the "Technological Standard of Slope Engineering Construction" (GB503302002), Side slope belongs to first-grade slope engineering, as shown in Fig. (5) [6].

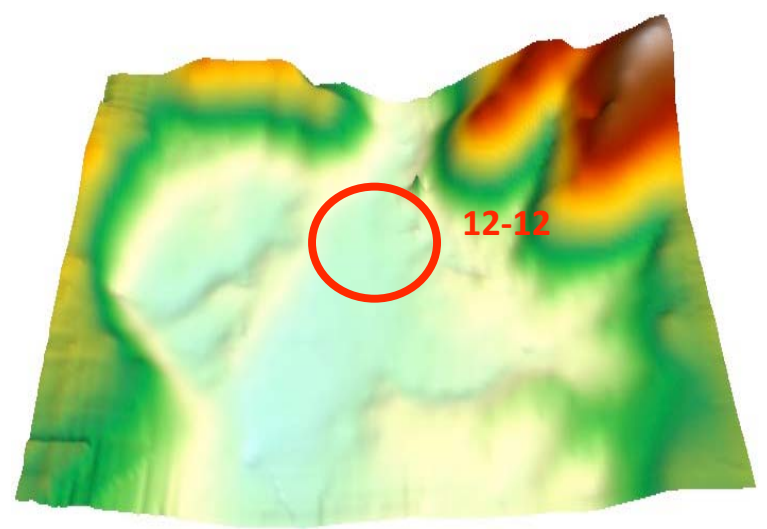

Fig. (5). 3D topographical map and the satellite image map. 
According to the site geological survey and the analysis of the rock mass structural plane, the part of rock slope is in the state of more stable and stable under current situations. According to the site survey, no large-scale landslide slope was found under current situations. The stratum structure, slope characters and slope type are very different in paragraphs of the slope. The treatment scheme of every slope paragraph should be adjusted according to local conditions in order to get rid of landslide. The slope effective protection will be carried out to combine with the site plan, factory construction and environment protection.

\subsection{The Modular Calculation of Limit Equilibrium}

The limit equilibrium method was used to estimate the stability of the sliding section. The calculation formula has satisfied the requirement from "Specification of Design and Construction for Landslide" (DZ/T0219-2006). According to the rock mechanical test results, the mechanical parameters of the rock layer were listed in Table $\mathbf{1}$.

Table 1. The soil properties of the slope section in 12-12.

\begin{tabular}{|c|c|c|c|c|}
\hline & soil type & $c^{\prime}\left(\mathrm{kN} / \mathrm{m}^{2}\right)$ & $\phi^{\prime}(\mathrm{deg})$ & $\gamma\left(\mathrm{kN} / \mathrm{m}^{3}\right)$ \\
\hline \hline Layer 1 & silty clay & 18 & 10 & 18.5 \\
\hline Layer 2 & limestone & 500 & 35 & 23 \\
\hline
\end{tabular}

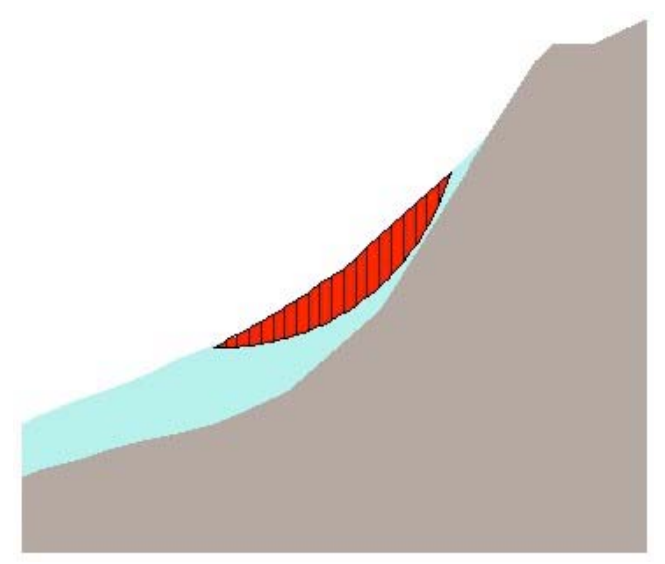

Fig. (8). Slope section in 12-12 and the most unfavorable slip plane area.

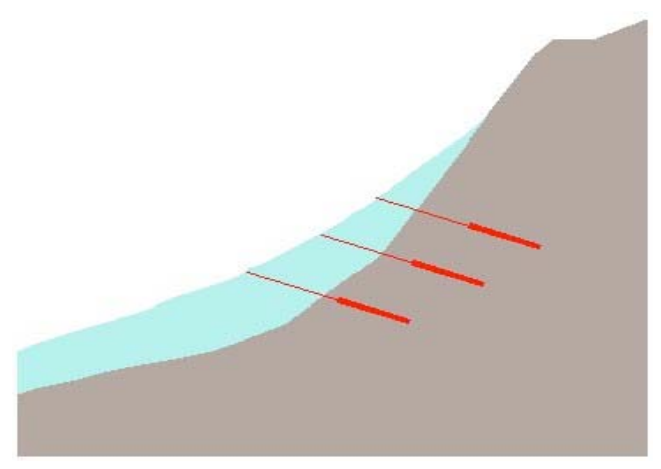

Fig. (9). Bolt support in the 12-12 area.
The slip plane searched by the simplified bishop method is shown in Fig. (8). The safety factors to be calculated is 1.146, which less than 1.30 and the slope should be governed.

\subsection{The Calculation of Design Models of the Bolt Support}

The support for 12-12 slope selected the bolt + ecoconcrete. According to the design principle of the bolt support, combining the skipping force with the row number of the bolt, we can determine that the anchored force is 185.6 $\mathrm{KN}$, the angle between bolt and the horizontal plane is $20^{\circ}$ and the bolt should be used the refined rebar with diameters of $25 \mathrm{~mm}$. After calculation, stratum and bond length of the grouting material was $\mathrm{Lr} \geq 5.84 \mathrm{~m}$, grouting material and bond length of the bolt was $\mathrm{Lg} \geq 0.61 \mathrm{~m}$. We determine that the design value of anchorage length at the non-slumping area is $6 \mathrm{~m}$, arrangement number of the Soil Nail is 3 , the spacing of bolt is $2.4 \times 2.5 \mathrm{~m}$, the hole diameter was $35 \mathrm{~mm}$, grouting $\mathrm{M} 30$, the thickness of the Eco-Concrete is $15 \mathrm{~cm}$. The cross sectional design at the non-slumping area is shown in Fig. (9). According to the design above, the safety factor of the bolt support is 1.553 .

\section{CONCLUSION}

Along with the deep development of GIS theory, Geographic Information System (GIS) has played an important role in slope stability evaluation by its powerful data tackling ability and spatial analysis function. A comprehensive evaluation system on slope stability was developed based on the GIS technology and Combined with slope stability evaluation method (Fuzzy Evaluation Method, Limit Equilibrium Method, Finite Element Method, Monte Carlo Method), which can provide the geographic information, accurate analysis result and reasonable design schemes for slope stability evaluation and management. To take Sichuan Saide open slope for an example, we improved the safety factor from 1.146 before supporting to 1.553 after supporting, which is higher than the critical security value1.30. It showed that the scheme met the stability requirements and the design is reasonable. This bolt support design integrated GIS, Engineering Technology and design specifications, which not only can give an effective management to the slope information, but also can evaluate the slope stability and generate the bolt support design programs. This bolt support module can realize the visual display and the visual management of every evaluation phase of the slope. The whole process for evaluating and developing did not relied on any other commercial software, without the help of the associated interfaces. Thus the computational speed was greatly improved and saved a lot of time.

\section{CONFLICT OF INTEREST}

The authors confirm that this article content has no conflict of interest.

\section{ACKNOWLEDGEMENTS}

The paper is funded by the special scientific research and reform project of promoting talent training: Study on soil- 
compacting effects induced by earth pressure balance shield machine cutter head and their simulation (14085-11).

\section{REFERENCES}

[1] S. C. Tang, L. N. Tao, Q. Y. Chen, and Z. Chen, "Design System for the Slope Support of Highway Based on GIS", Chinese Journal of Underground Space and Engineering, Vol.1, No. 2, pp. 258-262, 273, 2005.

[2] M. W. Xie, and M. F. Cai, "The Theory and Practice of Information Slope Engineering", Science Press: Beijing, 2005.

[3] Geotechnical Anchor Specification (CECS22: 2005), "The Technical Specification of Standardization Society of China Engineering Construction", China Planning Press: Beijing, 2005.

[4] H. C. Chen, C. Li, and L. Wang, "Research on Simplified Calculation Method of Internal Stability in Soil-nailing Supporting Structure", Journal of Shandong University of Science and Technology (Natural Science), Vol.23, No.2, pp. 33-36, 2004
[5] W. D. Deng, "Comprehensive Technique on the Stability of Highway Slope", Beijing: China Communications Press, 2006.

[6] H. Y. Zhao, "The Research on Forecasting and the Forewarning Technology of the slope instability disaster". M.S. thesis, North China University of Technology, Beijing, 2010.

[7] C. G. Zhao, B. Bai, and Y. X. Wang, "Principles of the Soil Mechanics", Beijing: Publishing House of Tsinghua University, 2004.

[8] C. C. Zhang, "Theory and Method of Spatial Analysis in GIS", Publishing House of Wuhan University: Wuchang, 2004.

[9] M. W. Xie, and M. F. Cai, "The Theory and Practice of Information Slope Engineering", Science Press: Beijing, 2005.

[10] Y. X. Zhang, H. J. Wen, and M. Ou, "Intelligence Prediction Theory of the Landslide Hazard and its Application", Science Press: Beijing, 2005.

[11] X. L. Hu, and H. M. Tang, "Research and Application of the GIS System in Slope Engineering", Publishing House of China University of Geosciences: Beijing, 2005.

(C) Zhao and Wu; Licensee Bentham Open.

This is an open access article licensed under the terms of the (https://creativecommons.org/licenses/by/4.0/legalcode), which permits unrestricted, noncommercial use, distribution and reproduction in any medium, provided the work is properly cited. 